\title{
Estimating Willingness-to-Pay with Random Valuation Models: An Application to Lake Sevan, Armenia
}

\author{
Hua Wang ${ }^{1}$ \\ Benoit Laplante \\ Xun Wu \\ Craig Meisner
}

\begin{abstract}
This paper presents a case study of willingness-to-pay (WTP) estimation using random valuation models. A contingent valuation survey was conducted in Yerevan, Armenia to estimate people's WTP for the protection of Lake Sevan. Three different formats - open-ended, closed-ended, and the stochastic payment card (SPC) approach - were employed with split random samples. WTP models with heterogeneous errors were constructed and estimated with the survey data. The SPC approach produces a higher estimation of the mean WTP than both the open-ended and closedended approaches, while results from the open-ended and closed-ended elicitation formats are similar. Furthermore, contrary to research findings obtained in the United States, this study finds higher WTP estimations with mail surveys than with personal interviews.
\end{abstract}

JEL Codes: D80, Q21

World Bank Policy Research Working Paper 3367, August 2004

The Policy Research Working Paper Series disseminates the findings of work in progress to encourage the exchange of ideas about development issues. An objective of the series is to get the findings out quickly, even if the presentations are less than fully polished. The papers carry the names of the authors and should be cited accordingly. The findings, interpretations, and conclusions expressed in this paper are entirely those of the authors. They do not necessarily represent the view of the World Bank, its Executive Directors, or the countries they represent. Policy Research Working Papers are available online at http:/lecon.worldbank.org.

\footnotetext{
${ }^{1}$ Corresponding address: Hua Wang, World Bank, MC2525, 1818 H St., N.W., Washington, DC 20433, USA; Email: HWANG1@,worldbank.org.
} 


\section{Acknowledgements}

We express our sincere thanks to Sasun Tsirunyan and his survey team for their diligent and professional effort to conduct the large survey work described in this paper. We would also like to thank Viktor Adamowicz, Maureen Cropper, Sari Soderstrom, and Dale Whittington for their comments and suggestions. Finally, we would like to thank the Ministry of Nature Protection of the Republic of Armenia for its continuous support with the design and implementation of this research. 


\section{Introduction}

It is generally recognized that respondents in contingent valuation surveys may not be certain about the value they attach to the commodity or service subject to valuation. ${ }^{2}$ Previous studies have addressed this issue in a number of ways. Several researchers have added a “don't know" or "not sure" option to the traditional dichotomous choice (DC) contingent valuation format (e.g. Wang 1997b and Carson et al. 1998). Other researchers have added follow-up questions to assess the uncertainty of answers with a certainty scale ranging from 1 (very certain) to 10 (very uncertain), or from $0 \%$ (uncertain) to 100\% (certain) (e.g., Li and Mattsson 1995 Champ et al. 1997). Yet, other researchers have designed a polychotomous choice format and a multiple bounded model to provide respondents with multiple options ranging from "definitely yes" to “definitely no" (e.g., Ready et al. 1995, Welsh and Poe 1998, and Alberini et al. 2003).

In contrast with the traditional assumption that each individual has a certain, single, and true value of a commodity or service in his/her mind at the time of the survey, Wang (1997b) explicitly introduced a concept of individual valuation distribution, or random valuation model. To measure an individual's valuation distribution, a stochastic payment card (SPC) approach was designed and applied in an air quality valuation study (Wang 1997a, Wang and Whittington 2000). The SPC approach offers to respondents a list of prices and an associated numeric likelihood matrix describing how likely the respondent would agree to pay the various offered prices. Using this information, it is then possible to estimate the individual's valuation distribution with the likelihood data based on the random valuation model.

\footnotetext{
${ }^{2}$ See Cameron and Quiggin 1994, DuBourg et al. 1994, Li and Mattsson 1995, Ready et al. 1995, Wang 1997a \& b, Welsh and Poe 1998, Layton 2000, Berrens et al. 2002, and Alberini et al. 2003.
} 
In this paper, we further analyze WTP estimations with random valuation models, and present an empirical study in which individuals' valuation distributions are estimated using not only the SPC approach, but also the traditional open-ended and closed-ended approaches. As suggested by the random valuation theory, WTP models with heterogeneous errors are constructed and estimated with the survey data. Both the mean values and variances of WTP distribution are estimated and compared. Furthermore, in this paper we not only elicit and compare WTP from three different solicitation formats, but we also apply these formats to both a mail survey and a personal interview. To our knowledge, such an exercise has thus far not been performed.

Data collection was conducted in Yerevan, Armenia, to elicit people's WTP for the protection of Lake Sevan, an important historical, cultural, and economic asset of the Armenian nation. The WTP estimation with the SPC approach is found to be higher than the estimations given by the closed-ended approach and the open-ended approach. This result is opposite to the finding given by Wang and Whittington (2000) where a higher estimation with the closed-ended approach than with the SPC approach is reported of people's WTP for air question improvement in Sofia, Bulgaria. Furthermore, we find the closed-ended approach to produce WTP estimation very close to the estimation provided by the open-ended approach. Finally, contrary to the research findings obtained in the United States, the mail survey conducted in Yerevan provides a higher estimation of WTP than the WTP estimated from personal interviews.

In the next section, we provide a summary of the WTP models and the estimation methods associated with the three contingent valuation approaches employed in this study. In Section III, 
we briefly describe the context of the existing study, along with the research design and survey implementation. Results are presented in Section IV. We offer concluding remarks in Section V.

\section{The Models}

Several different sources of uncertainty may be imbedded in an individual's valuation of a commodity or service. ${ }^{3}$ Uncertainty may first exist with respect to the commodity in question: Individuals may not be certain about the quality of the commodity. Even if the quality of a commodity could be completely known, an individual may still not be certain about how the commodity in question is to be used. Uncertainty may also exist in the market. The monetary value of a commodity to an individual can be influenced by the prices of both substitute and complementary goods or services. Furthermore, uncertainty may exist with an individual's own situation and preferences: Individuals are sometimes uncertain about their future incomes, and people's tastes may change over time. In the context of contingent valuation surveys, because of the hypothetical nature of the valuation tasks, individuals may face other uncertain factors, such as the terms of provision of a public good.

A general valuation framework under uncertainty can be constructed as follows. Let the value of an individual's utility function, $\mathrm{V}_{0}$, at the status quo, $\mathrm{E}_{0}$, be:

$$
\text { (1) } \mathrm{V}_{0}=\mathrm{V}\left(\mathrm{Y}, \mathrm{P}, \mathrm{E}_{0}, \mathrm{Z}, \varepsilon\right)
$$

where $\mathrm{Y}$ is income; $\mathrm{P}$ is a price vector; $\mathrm{Z}$ is a vector of socioeconomic variables; $\mathrm{E}_{0}$ is an initial environmental quality; and $\varepsilon$ represents uncertain factors which are not reflected in $\mathrm{Y}, \mathrm{P}, \mathrm{E}_{0}$, and

\footnotetext{
${ }^{3}$ See Wang $1997 \mathrm{a} \& \mathrm{~b}$ for further details.
} 
Z. Assume that an individual is willing to pay a maximum amount of WTP for an improvement of the level of environmental quality from $E_{0}$ to $E_{1}$ such that:

(2) $\mathrm{V}_{0}\left(\mathrm{Y}\right.$-WTP, $\left.\mathrm{P}, \mathrm{E}_{1}, \mathrm{Z}, \varepsilon\right)=\mathrm{V}_{0}\left(\mathrm{Y}, \mathrm{P}, \mathrm{E}_{0}, \mathrm{Z}, \varepsilon\right)$

Solving for WTP yields,

(3) $\quad \mathrm{WTP}=\mathrm{WTP}\left(\mathrm{Y}, \mathrm{P}, \mathrm{E}_{0}, \mathrm{E}_{1}, \mathrm{Z}, \varepsilon\right)$

WTP is a random variable, and equation (3) can be rewritten as,

(4) $\quad \mathrm{WTP}=\mathrm{E}[\mathrm{WTP}]+\varepsilon_{1}$

where $\mathrm{E}[\bullet]$ is an expectation transformation, and $\varepsilon_{1}$ is a random term with a mean value of zero. Assume $\mu=\mathrm{E}[\mathrm{WTP}]$, and the standard variance of $\varepsilon_{1}$ is $\sigma$. Then, the individual's WTP has a distribution with a mean $\mu$ and a variance $\sigma^{2}$. One may expect that the mean and the variance are different across individuals.

To further analyze the WTP, one may assume that individual i's WTP function has the following specification:

(5) $\quad \mathrm{WTP}_{\mathrm{i}}=\beta_{0}+\mathrm{x}_{\mathrm{i}}^{\prime} \beta+\varepsilon_{\mathrm{i}}$ 
where $x_{i}$ is a vector of explanatory variables with unknown coefficients $\beta ; \beta_{0}$ is an unknown constant term; $\varepsilon_{\mathrm{i}}$ is a random term with mean zero and variance $\sigma_{\mathrm{i}}^{2}$. Note that $\varepsilon_{\mathrm{i}}=\varepsilon_{1}+\varepsilon_{2}$, where $\varepsilon_{1}$ is the random term in individual i's WTP function as shown in (4), while $\varepsilon_{2}$ is the error caused by a researcher specifying a model as shown in equation (5), which also has a mean value of zero. Thus, $\varepsilon_{\mathrm{i}}$ simply represents the summation of uncertainties to both respondent $i$ in formulating his/her WTP, and a researcher in modeling the WTP function. The ratio of $\varepsilon_{\mathrm{i}} / \sigma_{\mathrm{i}}$ can be assumed to have a cumulative distribution function $\mathrm{F}(\bullet)$, which could be normal, logistic, Weibull, or any other distribution function. The conditional mean value of $\mathrm{WTP}_{\mathrm{i}}$ is $\mu_{\mathrm{i}}=\beta_{0}+\mathrm{x}_{\mathrm{i}}^{\prime} \beta$.

With an open-ended CV question format, an individual is assumed to give a value based on his/her WTP distribution as of equation (4). Model (5) can be estimated with the open-ended CV survey data by using the general formulation for testing and correcting heteroscedasticity proposed by Harvey (1976):

$$
\sigma_{\mathrm{i}}^{2}=\sigma^{2}\left[\exp \left(z_{\mathrm{i}}^{\prime} \gamma\right)\right]^{2}
$$

where $z_{i}$ is a vector of individual i's characteristics; $\gamma$ is the associated vector of coefficients of $z$. If $\gamma=0$, then the model shown in equation (5) reduces to a homogeneous model, which has been traditionally used in analyzing $\mathrm{CV}$ data ${ }^{4}$.

\footnotetext{
${ }^{4}$ Then the hypothesis for testing the stochastic theory as proposed in Wang $1997 \mathrm{~b}$ with the open-ended CV data reduces to testing whether $\gamma=0$ (see Greene 1993).
} 
With a closed-ended or dichotomous choice CV question format, the yes/no answers can be modeled as follows,

$$
\begin{aligned}
& \operatorname{Pr}(\text { yes }) \quad=\operatorname{Pr}\left(\beta_{0}+x_{i}^{\prime} \beta+\varepsilon_{i}>t_{i}\right) \\
& =\operatorname{Pr}\left(\varepsilon_{\mathrm{i}}>\mathrm{t}_{\mathrm{i}}-\beta_{0}-\mathrm{x}_{\mathrm{i}}^{\prime} \beta\right) \\
& =\operatorname{Pr}\left[\varepsilon_{i} / \sigma_{i}>\left(t_{i}-\beta_{0}-x_{i}^{\prime} \beta\right) /\left(\sigma * \exp \left(z_{i}^{\prime} \gamma\right)\right)\right] \\
& =1-\mathrm{F}\left[\left(\mathrm{t}_{\mathrm{i}}-\beta_{0}-\mathrm{x}_{\mathrm{i}}^{\prime} \beta\right) /\left(\sigma^{*} \exp \left(\mathrm{z}_{\mathrm{i}}^{\prime} \gamma\right)\right)\right] \\
& \text { (8) } \operatorname{Pr}(\text { no }) \quad=\operatorname{Pr}\left(\beta_{0}+\mathrm{x}_{\mathrm{i}}^{\prime} \beta+\varepsilon_{\mathrm{i}}<=\mathrm{t}_{\mathrm{i}}\right) \\
& =F\left[\left(t_{i}-\beta_{0}-x_{i}^{\prime} \beta\right) /\left(\sigma^{*} \exp \left(z_{i}^{\prime} \gamma\right)\right)\right]
\end{aligned}
$$

where $t_{i}$ is the price offered to respondent $i$. The log likelihood is given by:

(9) $\quad \ln \mathrm{L}$

$$
\begin{aligned}
& =\Sigma\left\{\mathrm{y}_{\mathrm{i}}^{*} \ln \operatorname{Pr}(\mathrm{yes})+\left(1-\mathrm{y}_{\mathrm{i}}\right) * \ln \operatorname{Pr}(\mathrm{no})\right\} \\
& =\Sigma\left\{\mathrm { y } _ { \mathrm { i } } ^ { * } \operatorname { l n } \left[1-\mathrm{F}\left[\left(\mathrm{t}_{\mathrm{i}}-\beta_{0}-\mathrm{x}_{\mathrm{i}}^{\prime} \beta\right) /\left(\sigma^{*} \exp \left(\mathrm{z}_{\mathrm{i}}^{\prime} \gamma\right)\right)\right]\right.\right. \\
& +\left(1-\mathrm{y}_{\mathrm{i}}\right) * \ln \left[\mathrm{F}\left[\left(\mathrm{t}_{\mathrm{i}}-\beta_{0}-\mathrm{x}_{\mathrm{i}}^{\prime} \beta\right) /\left(\sigma^{*} \exp \left(\mathrm{z}_{\mathrm{i}}{ }^{\prime} \gamma\right)\right)\right]\right.
\end{aligned}
$$

where $\Sigma$ denotes the summation over all $i$. If respondent i's answer is "yes", then $y_{i}=1$, while $y_{i}$ $=0$ if the answer is "no". Because of the existence of price $t_{i}$, all parameters in the likelihood function (9) can be identified.

The stochastic payment card (SPC) approach proposed by Wang (1997a) can be employed to estimate an individual's valuation distribution as shown in equation (4). An example of the SPC approach, which is similar to the multiple bounded dichotomous choice model employed by 
Welsh et al (1998), is presented in Appendix I, in which numeric likelihood values are associated with verbal likelihood references. An enumerator presents to a respondent a stochastic payment card which contains a list of different prices. Respondents are asked how likely they would agree to pay each of the amounts shown in the card. Respondents are asked to select a number as the likelihood or probability that they would agree to pay. After a respondent finishes selecting likelihood values to all prices listed, a likelihood matrix can then be constructed. ${ }^{5}$

The probability that a utility maximizer with a cumulative valuation distribution function $\mathrm{F}(\bullet)$ would accept the offer presented in the card is:

$$
\operatorname{Pr}(\text { yes }) \quad=\operatorname{Pr}\{\mathrm{WTP}>\mathrm{t}\}=1-\mathrm{F}(\mathrm{t})
$$

where WTP is the individual's value for a commodity and $\mathrm{t}$ is the price. The cumulative valuation distribution function $\mathrm{F}(\bullet)$ in equation (10), as well as the valuation probability density function, the mean and the variance of the probability function can be estimated with the likelihood matrix data obtained with the SPC approach.

The estimation of the valuation distribution is a relatively simple exercise. From equation (10), we have $\mathrm{P}_{\mathrm{ij}}=1-\mathrm{F}_{\mathrm{i}}\left(\mathrm{t}_{\mathrm{ij}}\right)$, where $\mathrm{P}_{\mathrm{ij}}$ is individual i's probability (the number circled by respondent $\mathrm{i}$ on the stochastic payment card) of agreeing to pay the price of $\mathrm{t}_{\mathrm{ij}}$ indicated at the $j$ th payment point; $\mathrm{F}_{\mathrm{i}}(\bullet)$ is the person $i$ 's cumulative valuation distribution function. By assuming a specific functional form for $\mathrm{F}_{\mathrm{i}}(\bullet)$, then the parameters in $\mathrm{F}_{\mathrm{i}}($.$) - the mean \mu_{\mathrm{i}}$ and the standard

\footnotetext{
${ }^{5}$ For more discussions on this issue, see Wang 1997a or Wang and Whittington 2000.
} 
variance $\sigma_{\mathrm{i}}$ of individual i's valuation distribution can be estimated. For example, if a normal distribution is assumed for $\mathrm{F}(\bullet)$, we have,

$$
\begin{aligned}
& P i j=1-\Phi\left(\frac{\mu i-t i j}{\sigma i}\right) \\
& t i j=\mu i+\sigma i \Phi^{-1}(1-P i j)
\end{aligned}
$$

With a set of $\mathrm{t}_{\mathrm{ij}}$ 's and $\mathrm{P}_{\mathrm{ij}}$ 's, a simple regression can be used to estimate $\mu_{\mathrm{i}}$ and $\sigma_{\mathrm{i}}$.

After $\mu_{\mathrm{i}}$ and $\sigma_{\mathrm{i}}$ are estimated for each individual i with the likelihood data, regressions can be conducted to analyze the determinants of the mean and the variance, as did for the open-ended and the closed-ended CV data. Specifically, let,

$$
\begin{aligned}
& \mu_{i}=\beta_{0}+x_{i}^{\prime} \beta+e_{1} \\
& \sigma_{i}=v_{0}+z_{i}{ }^{\prime} v+e_{2}
\end{aligned}
$$

where $\mathrm{x}$ and $\mathrm{z}$ are determinants of the mean and the variance; $\beta$ and $v$ are coefficients to be estimated; e1 and e2 are random errors which are homogeneous.

The advantage of the two-stage approach developed above is that the mean and the variance are estimated for each individual, and the final value estimation does not rely on econometric model specification and estimation. As a result, less model specification biases may be introduced. However, the coefficient estimations at the second stage are less efficient than the following combined modeling approach. 
In equation (10), let $\mathrm{q}_{\mathrm{ij}}=\Phi^{-1}\left(1-\mathrm{P}_{\mathrm{ij}}\right)$. Substituting (11) into (10) yields the following:

$$
\mathrm{t}_{\mathrm{ij}}=\beta_{0}+\mathrm{x}_{\mathrm{i}}^{\prime} \beta+\left(v_{0}+\mathrm{z}_{\mathrm{i}}{ }^{\prime} v\right) \mathrm{q}_{\mathrm{ij}}+\mathrm{e}_{3}
$$

Likelihood data from different respondents can be pooled together to estimate equation (13) as well as the models in $(12)^{6}$. More discussions about model estimation will be provided in section IV where appropriate.

\section{The Lake Sevan Study}

\section{III.1 Background}

The Republic of Armenia has a total area of approximately $29,740 \mathrm{~km}^{2}$ making it the smallest of the former Soviet republics. The country is dominantly mountainous with $72 \%$ of land above $1,500 \mathrm{~m}$. Approximately $47 \%$ of the total area is under agricultural use or grazing. A wide variety of habitats is found over the small territory of Armenia, including deserts, semideserts, mountain meadows and steppes, forests, wetlands, and alpine lakes.

Located to the northeast of the capital city Yerevan, Lake Sevan is the largest high altitude reservoir of fresh water in the Transcaucasus, and is one of the largest alpine lakes in the world with a total surface area of $1,248 \mathrm{~km}^{2}$ at $1,916 \mathrm{~m}$ above sea level. Its present length along the main axis is $74 \mathrm{~km}$; the average and maximum widths are $19 \mathrm{~km}$ and $32 \mathrm{~km}$, respectively. Its watershed covers an area of $4851 \mathrm{~km}^{2}$, about one-sixth of the country's area.

\footnotetext{
${ }^{6}$ As discussed in Wang 1997a, the answers to the prices lower than the highest price where a respondent gives a "definitely yes" and higher than the lowest price where a respondent gives a "definitely no" should be excluded in the analyses. Therefore only one "definitely yes" and one "definitely no" will be included in the estimations.
} 
Lake Sevan has played a decisive role in Armenia's history. As such the lake has a very significant symbolic, cultural and historical importance to the Armenian people; indeed, it is often said that Lake Sevan defines the people of Armenia. Furthermore, Lake Sevan has contributed and continues to contribute to Armenia's economy by providing water resources for agricultural, industrial and energy production needs.

In the late $1920 \mathrm{~s}$, Soviet engineers started to examine the potential for a more intensive utilization of Lake Sevan water as a source of hydroelectric power, and irrigation in the Ararat Valley. In 1930, a plan was developed to withdraw water at a rate of 1,025 million cubic meters (Mm3) a year: $650 \mathrm{Mm} 3$ would be used for hydro power generation, and $375 \mathrm{Mm} 3$ would be used to irrigate 130,000 ha of land. To achieve this, discharge of water into the Razdan River had to be increased from $50 \mathrm{Mm} 3$ a year to approximately $700 \mathrm{Mm} 3$. Over the course of only 60 years, the level of the lake dropped by $18 \mathrm{~m}$; its surface area decreased from 1416 to $1239 \mathrm{~km}^{2}$; and the volume of water in Lake Sevan fell by more than $40 \%$ (from 58.5 to $34.6 \mathrm{~km}^{3}$ ). ${ }^{7}$

The Government of the Republic of Armenia (RoA) recently expressed interest adopting a number of actions to protect Lake Sevan from further, perhaps irreversible, degradation, despite the extremely bad situation of its economy ${ }^{8}$. In 1995, under the auspices of a World Bank Institutional Development Fund grant, a program was implemented to examine Lake Sevan issues. Six working groups were established, each consisting of a team of local experts assisted by an external consultant to investigate critical components of watershed management and to

\footnotetext{
${ }^{7}$ Program of the Armenian Republic Water Resources Use, Book 1, Common Explanation, Ministry of Agriculture, 1992.
} 
recommend corrective actions for problems identified. Such actions, as strongly expressed by the Government of the RoA, include (1) preventing a further lowering of the level of Lake Sevan; (2) raising the level of the lake by at least 3 meters as quickly as possible, and (3) to continue the rise to $6 \mathrm{~m}$ if the ecosystem model determines that this addition is required. While various means can be used to achieve these objectives, the following three have retained the attention of the working groups and the interest of the government: (1) restricting the discharge of water from the lake to $370 \mathrm{Mm} 3$ a year; (2) the construction of a reservoir (Yeghvard Reservoir) downstream of Lake Sevan to store the water discharged from the lake in winter for irrigation use in summer (thus reducing the need to increase water discharges in summer); and (3) the completion of the Vorotan Diversion Project.

To this date, despite the alleged significant cultural, symbolic and economic value of the Lake, the willingness-to-pay of the population of Armenia to protect and prevent a further deterioration of the Lake has never been assessed. This is one of the major objectives of this study. A second important objective of this study is to test different contingent valuation formats: open-ended, closed-ended, and stochastic payment card.

\section{III.2 Research design and survey implementation}

In order to assess the willingness-to-pay of the Armenian population to protect and prevent a further deterioration of Lake Sevan, two WTP scenarios have been constructed and presented to Armenian respondents. These two scenarios correspond to the two alternative restoration targets under discussion - increasing the level of the lake by 3 meters, and preventing the water

\footnotetext{
${ }^{8}$ While the education level is high in Armenia, the economy has been very bad after the collapse of the former Soviet Union. The
} 
level from further decreasing, i.e. 0 meter increase. Insofar as the second important objective is concerned, three different valuation formats have been applied to split samples in the capital city of Yerevan. All respondents then received a similar same questionnaire except for the WTP question format and the restoration scenario. Figure 1 presents the sample design of the study in Yerevan.

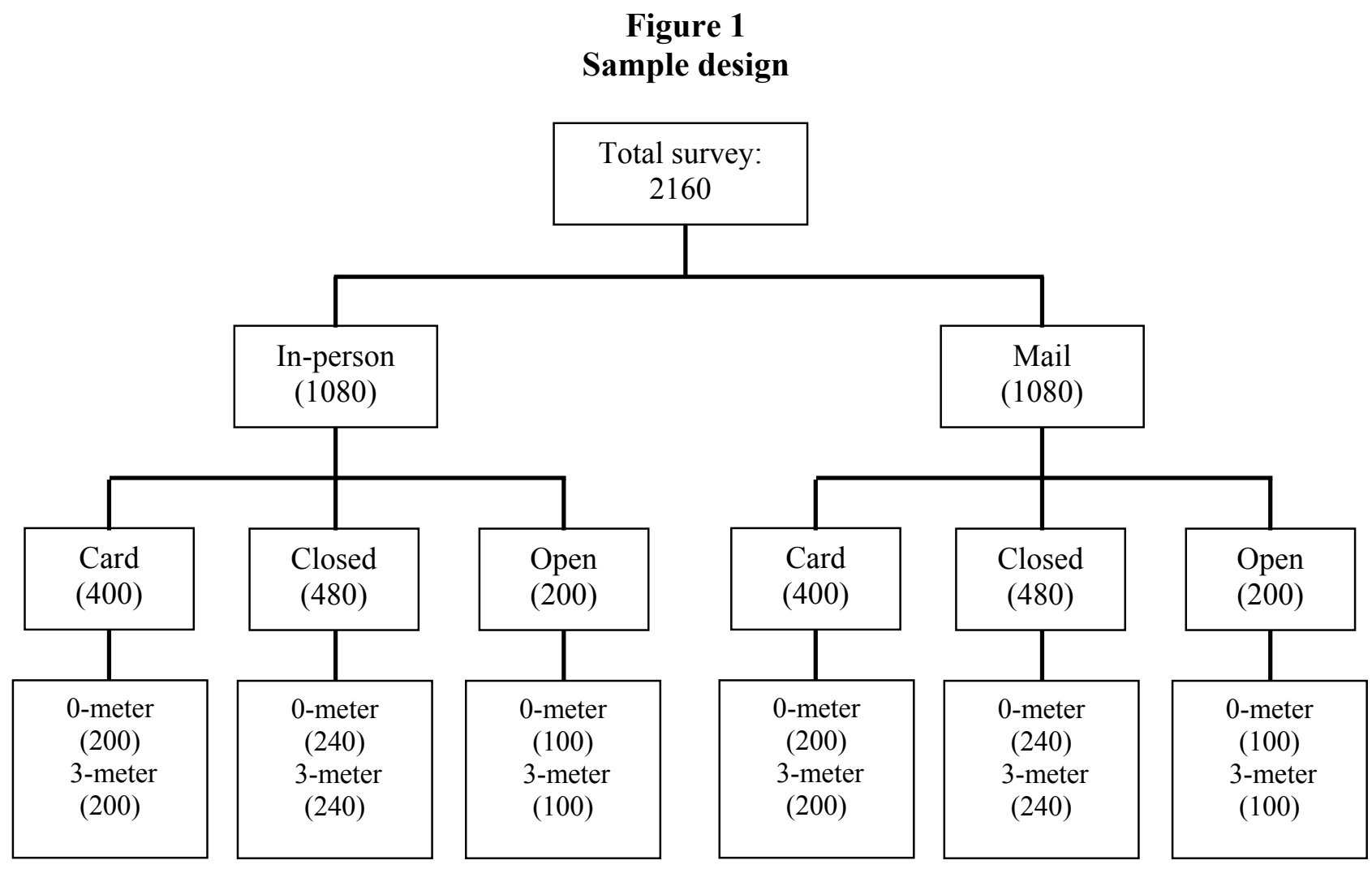

An equal number of mail surveys and personal interviews have been conducted (1080). For both the mail survey and the personal interview, a specific number of surveys has been assigned to the three WTP question formats: 400 for the stochastic payment card, 480 for the closed-ended approach, and 200 for the open-ended approach. These numbers are based upon the difference in the information efficiency of the open-ended and the closed-ended formats, and 
upon the special interests in the likelihood format. Within each WTP question format, the sample is split equally among the two restoration scenarios: 0 - meter and 3 - meter.

The questionnaire has been developed by the authors, Armenian government officials working on the Lake Sevan restoration action plan, and a team of 16 Armenians (professors, engineers, small business owners, high school teachers, university students, etc.) who were responsible for conducting the surveys. In addition to close consultation with the above individuals, extensive pre-tests were conducted in Yerevan, the country side of Armenia, and the areas surrounding the lake. The pre-tests focused particularly (but not only) on the presentation of the action plan, the impacts of the action plan, the WTP questions (especially the range of price values to present to the respondents), on the income and expenditure questions, and the ways of conducting the personal interview and the mail survey. Three internationally recognized contingent valuation experts in the U.S. and Canada were also consulted during the survey development.

The final version of the questionnaire included six parts: (1) environmental attitudes and perceptions; (2) Lake Sevan action plan; (3) contingent valuation questions; (4) socio-economic characteristics; (5) recreational use of Lake Sevan; and (6) interview debriefing questions. Excerpts of the questionnaire about the Lake Sevan action plan and the willingness-to-pay questions are provided in Appendix II. ${ }^{9}$ The monthly payments were proposed to be added to utility bills for a period of 3 years. Twenty-two follow-up questions were asked to assess

\footnotetext{
${ }^{9}$ The final version of the questionnaire can be obtained from the author and will be available on the internet.
} 
opinions with regard to the action plan, the impacts of the action plan, the project implementation and management, as well as the willingness-to-pay questions.

Charts and graphs (appendix III and IV) were also developed to help respondents understand the possible impacts associated with the changes of water level of the lake. For the case of a 3 - meter increase, three relevant situations were presented to the respondents: the current situation or no change; a 3 - meter increase in 15 years with the action plan, and a 2 meter decrease without the action plan. For the case of a 0 - meter change in the level of the lake, only two situations were relevant and presented to the respondents: the current status of the lake, and a 2 - meter decrease of the level of the lake.

An experienced local survey team, who had conducted several contingent valuation surveys before, was selected to participate in the survey development, and to conduct the surveys. Most of the team members had a part-time job, and regarded the survey work as a second job. The team was led by a university professor in Yerevan who has developed a long expertise with such exercise both within and outside Armenia. The survey team was trained by the authors during the survey development, the focus group studies and the pre-tests. Furthermore, the interview work was supervised by one of the authors closely in Yerevan. The survey was conducted between July and November of 2000.

The sample was selected from a detailed list of households in Yerevan based on the census of 1996, and the stratification method was used as the primary sampling strategy. Different versions of questionnaires were randomly assigned to the selected households. For the personal 
interviews, the interviewers visited the selected households, and a neighboring household was visited if a selected household had no persons at home who could take the interviews during the two planned visits made by the interviewers.

For the mail surveys, the questionnaire packages were first personally delivered to the doors of the selected households, and the selected households were visited again by the study team at a specified time and date to collect the finished questionnaires, normally 5 days after the initial delivery of the questionnaire. If the questionnaires were not finished at the specified time, the households would be notified and would be visited again at another specified time and date. If the household failed again to finish the questionnaire, a neighboring household would be selected. While this method of conducting the mail survey was rather expensive, it was deemed the only appropriate way of conducting this particular survey given that Yerevan does not have a well functioning mailing system. ${ }^{10}$ All households who participated in the interview and the survey received a small gift as a token of appreciation of their participation.

For the mail survey, the response rate reached $80 \%$, with a refusal rate $6 \%$. Among the questionnaires that were returned, $95 \%$ were completed. For the personal interviews, the response rate also reached approximately $80 \%$, with a refusal rate of $10 \%$.

\footnotetext{
${ }^{10}$ For example, mailboxes in apartment buildings were (and still are) significantly destroyed, and could not have been used as a depository of the questionnaire.
} 


\section{Results}

\section{IV.1 Descriptive statistics}

Before we present the results of our analysis, it is of interest to examine first a number of statistics describing our sample set. Variables of interest are described in Table 1.

Table 1

Description of Variables Used in the WTP Analyses

\begin{tabular}{|c|c|}
\hline Variable & Description \\
\hline Inc & Household monthly income in Armenian Dram (AMD) in '000 \\
\hline Age & Age of individual (years) \\
\hline Male & $=1$ if the respondent is male; $=0$ otherwise \\
\hline Edu & Education of individual (years) \\
\hline Incfut & $\begin{array}{l}\text { Rank order score measuring how the individual thinks the household income may } \\
\text { change over the next } 5 \text { years (scale from } 1 \text { to } 5 \text { with } 1 \text { meaning a significantly } \\
\text { worse income than today, and } 5 \text { meaning a significantly better level of income } \\
\text { than today }\end{array}$ \\
\hline 3-meter & $=1$ for the 3 -meter scenario $;=0$ for the 0 -meter scenario \\
\hline Mail & $=1$ if a mail survey; $=0$ if a personal interview \\
\hline Visit & $=1$ if the individual visited the Lake Sevan in the past 12 months and 0 otherwise \\
\hline Recfut & $\begin{array}{l}=1 \text { if the individual would visit the lake for recreational purpose in the near future; } \\
=0 \text { otherwise }\end{array}$ \\
\hline Nuseval & $\begin{array}{l}\text { Rank order score measuring how the individual thinks the project would change } \\
\text { the historical, cultural, and symbolic value of the lake (scale from } 1 \text { to } 5 \text { with } 1 \\
\text { meaning a significantly worse situation than today, and } 5 \text { meaning a significantly } \\
\text { better situation than today }\end{array}$ \\
\hline Recreval & $\begin{array}{l}\text { Rank order score measuring how the individual thinks the project would change } \\
\text { the recreational value of the lake (scale from } 1 \text { to } 5 \text { with } 1 \text { meaning a significantly } \\
\text { worse situation than today, and } 5 \text { meaning a significantly better situation than } \\
\text { today }\end{array}$ \\
\hline Trusfund & $\begin{array}{l}\text { Rank order score measuring how the individual thinks the Trust Fund can be } \\
\text { effective implementing the action plan (scale from } 1 \text { to } 5 \text { with } 1 \text { meaning not } \\
\text { effective at all, and } 5 \text { meaning very effective. }\end{array}$ \\
\hline
\end{tabular}

* Closed-ended referendum bids: [100, 200, 400, 600, 800, 1000, 2000, 5000]

As shown in Table 2, the average monthly income of the households that participated in our survey was approximately 53 thousand $\mathrm{AMD}^{11}$ (equivalent to $100 \mathrm{USD}$ ), for an average household size of 4 persons. Approximately one-third of the households interviewed had no 
persons with paid employment, and $50 \%$ of the respondents were not employed. $40 \%$ of the respondents asserted that their households' incomes were far from enough to satisfy basic needs, and $32 \%$ said that their incomes were just enough for food. On the other hand, only $16 \%$ of the respondents said they expect their financial situation to worsen over the next 5 years. A small percentage of the respondents $(15 \%)$ declared receiving financial assistance from relatives or friends. Furthermore, $90 \%$ of the respondents owned their houses or apartments, and $84 \%$ owned a color TV, washing machine or telephone. In Yerevan, the average monthly electricity bill was 4300 AMD and the water bill 300 AMD.

Table 2

Descriptive Statistics of Major Variables in WTP Functions

\begin{tabular}{|l|c|c|}
\hline \multicolumn{1}{|c|}{ Variable } & Mean & Standard Deviation \\
\hline Inc & 53.94 & 51.55 \\
\hline Age & 43.77 & 13.78 \\
\hline Male & 0.34 & 0.47 \\
\hline Edu & 10.37 & 2.03 \\
\hline Incfut & 2.92 & 0.73 \\
\hline 3-meter & 0.50 & 0.50 \\
\hline Mail & 0.50 & 0.50 \\
\hline Visit & 0.57 & 0.50 \\
\hline Recfut & 0.24 & 0.43 \\
\hline Nuseval & 3.84 & 0.71 \\
\hline Recreval & 3.89 & 0.78 \\
\hline Trusfund & 2.85 & 0.94 \\
\hline
\end{tabular}

On matters pertaining to the environment, $88 \%$ of the respondents said they were generally concerned about the quality of the environment; $38 \%$ said they would contribute time or money to an environmental organization if requested; and $58 \%$ said they would contribute time or

\footnotetext{
${ }^{11}$ One US dollar equals about 530 ADM.
} 
money to support an environmental protection program in Armenia if asked. However, only $0.7 \%$ of the respondents were a member of an environmental organization.

Insofar as Lake Sevan itself is concerned, 95\% of the respondents had visited the lake in the past, and $74 \%$ of the respondents knew that the level of water in Lake Sevan had decreased significantly in the last 50 years, and $86 \%$ of the respondents thought the environmental condition of Lake Sevan had been getting worse over the past five years. Furthermore, 75\% of the respondents thought that the value of Lake Sevan as an important cultural heritage site for the people of Armenia would be damaged very significantly if no action were undertaken. About a half of the respondents thought that if the water level were to be maintained or raised, there would be less water for irrigation and energy generation today, but more in the future. $93 \%$ said that they felt protecting Lake Sevan was important or very important to them. However, only $5.8 \%$ of the respondents were aware of the existence of the Lake Sevan Action Plan.

\section{IV.2 The Open-ended Approach}

A total of 420 respondents were asked an open-ended WTP question. The open-ended WTP question faced by the respondents was: "What is the most your household would be willing to pay per month for 3 years to stabilize and prevent a further lowering of the lake (or to increase the water level for 3 meters in 15 years)?" As shown in Table 3, 49.1\% of respondents gave a positive number to this question in the personal interview context, and $54.8 \%$ did so in the mail survey. $38.1 \%$ of the respondents gave a zero bid in the personal interview, while $10.5 \%$ did so in the mail survey. The remaining respondents either gave no values or said "I don't know." 
Table 3

Statistics of WTP Bids to the Open-ended CV Questions

\begin{tabular}{|l|c|c|c|c|c|c|}
\cline { 2 - 7 } \multicolumn{1}{c|}{} & \multicolumn{2}{c|}{ Personal Interview } & \multicolumn{2}{c|}{ Mail Survey } & \multicolumn{2}{c|}{ Total } \\
\cline { 2 - 7 } \multicolumn{1}{c|}{} & Obvs. & $\%$ & Obvs. & $\%$ & Obvs. & $\%$ \\
\hline Positive bid & 103 & 49.1 & 115 & 54.8 & 218 & 51.9 \\
\hline Zero bid & 80 & 38.1 & 22 & 10.5 & 102 & 24.3 \\
\hline Don't know & 13 & 6.2 & 60 & 28.6 & 73 & 17.4 \\
\hline Missing value & 14 & 6.7 & 13 & 6.2 & 27 & 6.4 \\
\hline Total & 210 & 100 & 210 & 100 & 420 & 100 \\
\hline
\end{tabular}

The mean WTP estimations are presented in Table 4. For both the 0 - meter scenario and the 3 - meter scenario, the mean WTP estimations with the mail survey are much higher than from personal interviews. For the 0 - meter case, the mean WTP is 446 AMD with the mail survey, but only 201 AMD with the personal interview. For the 3 - meter case, the means are 495 AMD with the mail survey, and 213 AMD with the personal interview.

Table 4

Mean WTP - Open ended approach (AMD)

\begin{tabular}{|l|c|c||c|c|}
\cline { 2 - 5 } \multicolumn{1}{c|}{} & \multicolumn{2}{c||}{ Personal Interview } & \multicolumn{2}{c|}{ Mail Survey } \\
\cline { 2 - 5 } \multicolumn{1}{c|}{} & 0-meter & 3-meter & 0-meter & 3-meter \\
\hline Mean Value of the WTP & 201 & 213 & 446 & 495 \\
\hline St. Var. of the WTP & 374 & 595 & 881 & 776 \\
\hline \# of observations & 95 & 88 & 67 & 70 \\
\hline
\end{tabular}

A Tobit model has been constructed to analyze the determinants of the WTP. Results are presented in Table 5. Income, education, expectation of changes in future income, future use of the lake for recreational purposes, as well as the expected positive impact of the action plan on the recreational value of the lake all have positive and significant correlation with the WTP. Note that the 3 - meter scenario does not provide a significantly different value than the 0 - meter case. The mail survey gives a significantly higher estimation of WTP. It is also important to note that 
the greater the trust a respondent gave to the trust fund management, the higher the WTP. The variable Male has a positive correlation with the WTP but has a negative relationship with the variance function. Income, age and education have positive correlations with the variance of WTP.

Table 5

WTP Tobit Models with the Open-ended Approach

\begin{tabular}{|c|c|c|c|c|}
\hline & \multicolumn{2}{|c|}{ Without Variance Function } & \multicolumn{2}{|c|}{ With Variance Function } \\
\hline & Coefficient & t-value & Coefficient & t-value \\
\hline Constant & -2845.05 & -5.93 & -943.84 & -2.93 \\
\hline INC & 4.57 & 5.10 & 2.99 & 2.34 \\
\hline $\mathrm{AGE}$ & 0.94 & 0.26 & -0.97 & -0.45 \\
\hline MALE & 9.93 & 0.11 & 124.06 & 2.30 \\
\hline EDU & 84.90 & 3.47 & 11.45 & 0.86 \\
\hline INCFUT & 162.46 & 2.39 & 100.62 & 2.17 \\
\hline 3-meters & -89.63 & -0.97 & -26.83 & -0.49 \\
\hline MAIL & 441.80 & 4.59 & 227.09 & 4.19 \\
\hline VISIT & 281.85 & 2.61 & 211.71 & 3.76 \\
\hline RECFUT & 266.38 & 2.49 & 135.12 & 2.27 \\
\hline NUSEVAL & 97.98 & 1.36 & 23.31 & 0.50 \\
\hline RECREVAL & 81.52 & 1.19 & 11.82 & 0.27 \\
\hline TRUSFUND & 59.53 & 1.22 & 58.14 & 2.10 \\
\hline \multicolumn{5}{|c|}{ Variance Function } \\
\hline $\mathrm{INC}$ & & & 0.01 & 12.16 \\
\hline $\mathrm{AGE}$ & & & 0.01 & 2.26 \\
\hline MALE & & & -0.29 & -3.91 \\
\hline EDU & & & 0.17 & 5.44 \\
\hline Observations & 316 & & 316 & \\
\hline Log likelihood & -1762 & & -1697 & \\
\hline
\end{tabular}




\section{IV.3 The Closed-ended Approach}

960 respondents successfully completed the closed-ended or referendum CV surveys. Table 6 shows the distribution of responses to the referendum questions. A significant portion of respondents in mail survey answered "I don't know" to the referendum questions, while the number among respondents in the personal interview is much smaller, which is similar to the findings in the previous studies (Wang 1997a). The percentages of "yes" answers decrease to almost zero when the price increases to 5000 ADM.

Table 6

Distribution of Responses to the Closed-ended CV Questions

\begin{tabular}{|c|c|c|c|c|c|c|c|c|}
\hline Bid Amount & 100 & 200 & 400 & 600 & 800 & 1000 & 2000 & 5000 \\
\hline \multicolumn{9}{|c|}{ Mail Surveys } \\
\hline No decrease & & & & & & & & \\
\hline Yes (\%) & 86.7 & 58.6 & 39.3 & 20.7 & 26.9 & 22.2 & 10.7 & 3.3 \\
\hline No (\%) & 3.3 & 34.5 & 35.7 & 62.1 & 57.7 & 59.3 & 78.6 & 83.3 \\
\hline I don't know (\%) & 10.0 & 6.9 & 25.0 & 17.2 & 15.4 & 18.5 & 10.7 & 13.3 \\
\hline Total & 30 & 29 & 28 & 29 & 26 & 27 & 28 & 30 \\
\hline Increase 3 meters & & & & & & & & \\
\hline Yes (\%) & 63.0 & 71.4 & 28.0 & 24.0 & 10.0 & 20.7 & 3.6 & 0.0 \\
\hline No (\%) & 25.9 & 25.0 & 56.0 & 56.0 & 70.0 & 69.0 & 67.9 & 79.2 \\
\hline I don't know (\%) & 11.1 & 3.6 & 16.0 & 20.0 & 20.0 & 10.3 & 28.6 & 20.8 \\
\hline Total & 27 & 28 & 25 & 25 & 30 & 29 & 28 & 24 \\
\hline \multicolumn{9}{|c|}{ In-person Interview } \\
\hline No decrease & & & & & & & & \\
\hline Yes $(\%)$ & 72.4 & 66.7 & 36.7 & 23.3 & 13.8 & 13.8 & 0.0 & 0.0 \\
\hline No (\%) & 27.6 & 18.5 & 53.3 & 76.7 & 86.2 & 86.2 & 96.5 & 93.1 \\
\hline I don't know (\%) & 0.0 & 14.8 & 10.0 & 0.0 & 0.0 & 0.0 & 3.5 & 6.9 \\
\hline Total & 29 & 27 & 30 & 30 & 29 & 29 & 29 & 29 \\
\hline Increase 3 meters & & & & & & & & \\
\hline Yes (\%) & 82.8 & 57.1 & 37.0 & 34.5 & 13.8 & 13.8 & 10.7 & 0.0 \\
\hline No (\%) & 17.2 & 35.7 & 59.3 & 62.1 & 86.2 & 86.2 & 89.3 & 100.0 \\
\hline I don't know (\%) & 0.0 & 7.1 & 3.7 & 3.4 & 0.0 & 0.0 & 0.0 & 0.0 \\
\hline Total & 29 & 28 & 27 & 29 & 30 & 29 & 28 & 30 \\
\hline
\end{tabular}


The mean WTP is presented in Table 7. Note also that the mean WTP to increase the level of the lake by 3 meters is slightly lower than preventing a further lowering of Lake Sevan.

Table 7

Mean WTP - Closed-ended approach (AMD)

\begin{tabular}{|l|c|c||c|c|}
\cline { 2 - 5 } \multicolumn{1}{c|}{} & \multicolumn{2}{c||}{ Personal Interview } & \multicolumn{2}{c|}{ Mail Survey } \\
\cline { 2 - 5 } \multicolumn{1}{c|}{} & 0-meter & 3-meter & 0-meter & 3-meter \\
\hline Mean Value of the WTP & 273 & 222 & 505 & 455 \\
\hline St. Var. of the WTP & 394 & 414 & 327 & 294 \\
\hline St. error of the mean WTP & 84 & 60 & 149 & 84 \\
\hline \# of observations & 232 & 230 & 227 & 216 \\
\hline
\end{tabular}

The modeling results with the closed-ended approach are presented in Table 8. Probit models with heterogeneous variances are used for the analyses of the WTP answers. "Don'tknow" answers were deleted, because the observation is too small to provide meaningful estimation results. Income, Male, Visit, Recfut and Trusfund have positive correlations with the WTP answers, but the correlations are less significant than with the open-ended approach. Education again shows a significant, positive correlation with the variance term, as with the open-ended surveys. The mail survey produced a significantly higher estimation of WTP than the personal interview, which is consistent with the finding given by the open-ended approach. 
Table 8

Models with the Closed-ended Approach

\begin{tabular}{|c|c|c|c|c|}
\hline & \multicolumn{2}{|c|}{ Without Variance Function } & \multicolumn{2}{|c|}{ With Variance Function } \\
\hline & Coefficient & t-value & Coefficient & t-value \\
\hline Constant & -1.264 & -2.272 & -1.475 & -0.495 \\
\hline BID & -0.001 & -10.826 & -0.010 & -1.835 \\
\hline $\mathrm{INC}$ & 0.005 & 3.567 & 0.037 & 1.722 \\
\hline AGE & -0.003 & -0.597 & -0.042 & -0.930 \\
\hline MALE & 0.242 & 2.039 & 0.819 & 0.814 \\
\hline EDU & 0.004 & 0.129 & -0.378 & -1.065 \\
\hline INCFUT & 0.061 & 0.784 & 0.317 & 0.538 \\
\hline 3-meters & -0.169 & -1.469 & -0.514 & -0.585 \\
\hline MAIL & 0.322 & 2.809 & 2.357 & 1.419 \\
\hline VISIT & 0.097 & 2.289 & 0.743 & 1.319 \\
\hline RECFUT & 0.255 & 2.043 & 1.929 & 1.362 \\
\hline NUSEVAL & 0.032 & 0.361 & 0.104 & 0.156 \\
\hline RECREVAL & 0.035 & 0.445 & -0.109 & -0.191 \\
\hline TRUSFUND & 0.254 & 3.986 & 1.870 & 1.593 \\
\hline \multicolumn{5}{|c|}{ Variance Function } \\
\hline INC & & & -0.002 & -1.025 \\
\hline AGE & & & 0.006 & 0.744 \\
\hline MALE & & & 0.246 & 1.390 \\
\hline EDU & & & 0.171 & 4.443 \\
\hline Observations & 804 & & 804 & \\
\hline Log likelihood & -350 & & -346 & \\
\hline Mean WTP & 347 & & 350 & \\
\hline Std. Dev & 52 & & 473 & \\
\hline
\end{tabular}

\section{IV.4 The SPC Approach}

The results with the SPC approach are provided in Table 9, Table 10 and Table 11. In Table 9, simple statistics are provided showing for each price listed in the stochastic payment card, the percentages of respondents who choose a specific likelihood among the 11 options provided. 
Table 9

Statistics of Responses to the Likelihood Questions (\%)

\begin{tabular}{|c|c|c|c|c|c|c|c|c|c|c|c|c|}
\hline & $\mathbf{0 \%}$ & $10 \%$ & $20 \%$ & $30 \%$ & $40 \%$ & $50 \%$ & $60 \%$ & $70 \%$ & $80 \%$ & $90 \%$ & $100 \%$ & Obs. \\
\hline \multicolumn{13}{|c|}{ Personal Interview } \\
\hline \multicolumn{13}{|c|}{ No decrease } \\
\hline 0 & 0.5 & 0 & 0.5 & 0 & 0 & 3.1 & 0 & 0.5 & 1.0 & 0.5 & 93.9 & 195 \\
\hline 100 & 34.9 & 2.1 & 0 & 0 & 0 & 3.1 & 0.5 & 0 & 1.0 & 0.5 & 58.0 & 195 \\
\hline 200 & 50.8 & 0.5 & 0.5 & 0 & 0 & 6.2 & 0.5 & 1 & 1.5 & 2.1 & 36.9 & 195 \\
\hline 400 & 65.6 & 0.5 & 1.0 & 0 & 0.5 & 7.2 & 3.1 & 1 & 2.6 & 1.5 & 16.9 & 195 \\
\hline 600 & 79.0 & 1.0 & 1.0 & 0.5 & 0.5 & 4.6 & 3.1 & 1 & 1.5 & 1.5 & 6.2 & 195 \\
\hline 800 & 85.1 & 0.5 & 0.5 & 1.0 & 2.1 & 3.1 & 0.5 & 1.5 & 1.0 & 1.0 & 3.6 & 195 \\
\hline 1000 & 89.2 & 2.1 & 0 & 0 & 0.5 & 2.1 & 1.0 & 1.0 & 0 & 0.5 & 3.6 & 195 \\
\hline 2000 & 97.4 & 0 & 0 & 0.5 & 0 & 1.5 & 0 & 0 & 0 & 0 & 0.5 & 195 \\
\hline 5000 & 100 & 0 & 0 & 0 & 0 & 0 & 0 & 0 & 0 & 0 & 0 & 195 \\
\hline 10000 & 100 & 0 & 0 & 0 & 0 & 0 & 0 & 0 & 0 & 0 & 0 & 195 \\
\hline 20000 & 100 & 0 & 0 & 0 & 0 & 0 & 0 & 0 & 0 & 0 & 0 & 195 \\
\hline \multicolumn{13}{|c|}{3 meters increase } \\
\hline 0 & 1.5 & 0 & 0 & 0 & 0.5 & 3.6 & 0 & 0 & 1.0 & 1.5 & 91.8 & 195 \\
\hline 100 & 29.2 & 0 & 0.5 & 0 & 0 & 2.6 & 1.5 & 0 & 0.5 & 3.1 & 62.6 & 195 \\
\hline 200 & 45.1 & 0 & 1.0 & 0 & 1.5 & 8.7 & 3.6 & 1.0 & 1.5 & 4.1 & 33.3 & 195 \\
\hline 400 & 66.7 & 2.6 & 1.5 & 0.5 & 0.5 & 8.2 & 2.6 & 2.1 & 1.0 & 3.1 & 11.3 & 195 \\
\hline 600 & 78.0 & 1.5 & 2.6 & 1.5 & 0.5 & 4.1 & 0.5 & 1.5 & 0 & 2.1 & 7.7 & 195 \\
\hline 800 & 85.1 & 1.5 & 1.0 & 0.5 & 3.1 & 1.0 & 0.5 & 0.5 & 1.0 & 2.6 & 3.1 & 195 \\
\hline 1000 & 90.3 & 1.0 & 0.5 & 0 & 0.5 & 1.0 & 0 & 1.5 & 1.5 & 1.0 & 2.6 & 195 \\
\hline 2000 & 98.0 & 0 & 0 & 0 & 0.5 & 0 & 0.5 & 0 & 0 & 0 & 1.0 & 195 \\
\hline 5000 & 99.5 & 0 & 0 & 0 & 0 & 0 & 0 & 0 & 0 & 0 & 0.5 & 195 \\
\hline 10000 & 99.5 & 0 & 0 & 0 & 0 & 0 & 0 & 0 & 0 & 0 & 0.5 & 195 \\
\hline 20000 & 99.5 & 0 & 0 & 0 & 0 & 0 & 0 & 0 & 0 & 0 & 0.5 & 195 \\
\hline \multicolumn{13}{|c|}{ Mail Survey } \\
\hline \multicolumn{13}{|c|}{ No decrease } \\
\hline 0 & 9.7 & 0 & 0 & 0 & 0 & 1.5 & 0.5 & 0 & 0.5 & 0.5 & 87.2 & 195 \\
\hline 100 & 28.7 & 0 & 0.5 & 0 & 0.5 & 2.1 & 0.5 & 0.5 & 1.0 & 3.6 & 62.6 & 195 \\
\hline 200 & 53.9 & 1.0 & 0 & 0.5 & 0 & 1.5 & 1.0 & 0.5 & 2.1 & 2.6 & 36.9 & 195 \\
\hline 400 & 70.8 & 1.5 & 0 & 0.5 & 1.0 & 4.1 & 1.5 & 1.0 & 0 & 1.0 & 18.5 & 195 \\
\hline 600 & 78.5 & 1.0 & 1.5 & 0.5 & 1.0 & 1.5 & 1.0 & 0.5 & 0.5 & 1.0 & 12.8 & 195 \\
\hline 800 & 82.6 & 2.1 & 0 & 0 & 1.5 & 1.0 & 1.5 & 0.5 & 1.0 & 0.5 & 9.2 & 195 \\
\hline 1000 & 84.6 & 2.1 & 0.5 & 0.5 & 0.5 & 1.5 & 0.5 & 1.5 & 0 & 1.5 & 6.7 & 195 \\
\hline 2000 & 91.8 & 0 & 1.0 & 0.5 & 1.0 & 0.5 & 1.0 & 0.5 & 1.5 & 1.0 & 1.0 & 195 \\
\hline 5000 & 93.3 & 1.0 & 0.5 & 0 & 1.5 & 0.5 & 0 & 2.1 & 0 & 0.5 & 0.5 & 195 \\
\hline 10000 & 96.9 & 0.5 & 0.5 & 0 & 0 & 1.5 & 0.5 & 0 & 0 & 0 & 0 & 195 \\
\hline 20000 & 97.4 & 0.5 & 1.0 & 0.5 & 0 & 0 & 0.5 & 0 & 0 & 0 & 0 & 195 \\
\hline \multicolumn{13}{|c|}{3 meters increase } \\
\hline 0 & 6.4 & 0.5 & 0 & 0 & 0 & 0.5 & 0 & 0.5 & 0 & 0.5 & 91.5 & 189 \\
\hline 100 & 24.9 & 1.1 & 0 & 0.5 & 0.5 & 4.8 & 0 & 0 & 2.7 & 2.1 & 63.5 & 189 \\
\hline 200 & 46.6 & 0.0 & 0.5 & 1.1 & 0.5 & 3.2 & 1.6 & 1.1 & 1.6 & 4.2 & 39.7 & 189 \\
\hline 400 & 60.9 & 0.5 & 2.1 & 0.5 & 2.1 & 2.1 & 1.1 & 1.6 & 3.7 & 3.7 & 21.7 & 189 \\
\hline 600 & 70.9 & 1.6 & 0.5 & 1.6 & 1.1 & 3.7 & 1.1 & 1.1 & 2.1 & 1.1 & 15.3 & 189 \\
\hline 800 & 73.5 & 1.6 & 1.1 & 1.1 & 2.1 & 3.2 & 1.6 & 0 & 1.6 & 1.1 & 13.2 & 189 \\
\hline 1000 & 78.8 & 2.7 & 1.1 & 1.6 & 1.6 & 1.6 & 1.1 & 0.5 & 0.5 & 0.5 & 10.1 & 189 \\
\hline 2000 & 88.9 & 3.2 & 0 & 0 & 0.5 & 3.2 & 1.1 & 0 & 0 & 0.5 & 2.7 & 189 \\
\hline 5000 & 94.2 & 0.5 & 0 & 0.5 & 1.1 & 2.7 & 0.5 & 0 & 0 & 0 & 0.5 & 189 \\
\hline 10000 & 97.4 & 0 & 1.6 & 0 & 0.5 & 0.5 & 0 & 0 & 0 & 0 & 0 & 189 \\
\hline 20000 & 99.5 & 0 & 0 & 0 & 0.5 & 0 & 0 & 0 & 0 & 0 & 0 & 189 \\
\hline
\end{tabular}


Note that the percentage of "definitely yes" answers (or, 100\%) is decreasing fast from about $90 \%$ at a price of zero to about $5 \%$ at a price of $600-800 \mathrm{AMD}$ for the personal interviews and at a price of 1000-2000 AMD for the mail surveys. The percentage of "definitely no" answers (or, $0 \%$ ) increases steadily with the price offered. Less than $10 \%$ of the answers are not-sure answers, showing that Armenians are mostly decisive ${ }^{12}$ or binary. This number is very close to the number obtained with the closed-ended approach.

The mean WTP is presented in Table 10. Note also that the mean WTP to increase the level of the lake by 3 meters is similar to that of preventing a further lowering of Lake Sevan. Note again that the mail survey yields significantly higher mean WTP than the personal interview.

Table 10

Mean WTP - Stochastic payment approach (AMD)

\begin{tabular}{|l|c|c||c|c|}
\cline { 2 - 5 } \multicolumn{1}{c|}{} & \multicolumn{2}{c||}{ Personal Interview } & \multicolumn{2}{c|}{ Mail Survey } \\
\cline { 2 - 5 } \multicolumn{1}{c|}{} & 0-meter & 3-meter & 0-meter & 3-meter \\
\hline \multicolumn{1}{c|}{ Two-stage method } & & & & 764 \\
\hline Mean Value of the WTP & 349 & 344 & 894 & 720 \\
\hline Mean St. Var. & 471 & 426 & 144 & 142 \\
\hline \# of observations & 175 & 161 & & 883 \\
\hline Combined linear method & & & 740 & 411 \\
\hline Mean Value of the WTP & 466 & 510 & 349 & 158 \\
\hline Mean St. Var. & 337 & 333 & 162 & \\
\hline \# of observations & 148 & 147 & & \\
\hline
\end{tabular}

\footnotetext{
${ }^{12}$ One question was asked about the extent how a respondent understood the numeric likelihood presented in the payment card. About 50 percent of the respondents said they could clearly understand the difference of the numbers, about 20 percent said they
} 
Both the two-stage estimation approach and the combined one-stage approach developed in section II are used for the willingness-to-pay distribution estimation. As in Wang and Whittington (2000), 0.999 and 0.001 (instead of 1 and 0) are used to represent "definitely yes" and "definitely no" in estimating the means and the variances of the individual valuation functions. Prices higher than the first one with a "definitely no" answer and prices lower than the last one with a "definitely yes" answer are excluded from the analyses. On average, there are 3 observations (or, prices) getting into the valuation distribution estimation for each respondent. For the combined sample estimation, no weights are given to each observation. Therefore, the weight for a respondent in the combined estimation can be seen as the number of observations on his/her valuation distribution, which are given by the respondent in answering the likelihood questions. Robust regressions are used to estimate the parameters in the equations.

The econometric results are presented in Table 11. Income, education, future income expectation, previous visit of the lake, recreational use of the lake in the future, significant positive impact on the nonuse value of the lake, significant positive impact on the recreational value of the lake, and trust on the trust fund manager are all positively correlated with the mean value of individual's valuation distribution. The mail survey gives a significantly higher estimation of the mean WTP. The difference between the 0-meter scenario and the 3-meter scenario is not significant. Determinants of the variance functions are found consistent between the two stage method and the one stage method. Income, male and education are found positively correlated with the variance.

could vaguely understand the numbers, and the remaining 30 percent thought that the numbers did not make sense to them and 
Table 11

Models with the SPC Approach

\begin{tabular}{|c|c|c|c|c|}
\hline & \multicolumn{2}{|c|}{ Two-stage Method } & \multicolumn{2}{|c|}{ Combined linear Method } \\
\hline & Coefficient & $\mathrm{t}$-value & Coefficient & t-value \\
\hline Constant & -1782.524 & -3.585 & -1813.027 & -3.684 \\
\hline $\mathrm{INC}$ & 3.365 & 2.484 & 3.164 & 3.371 \\
\hline AGE & -1.888 & -0.440 & -0.160 & -0.041 \\
\hline MALE & 163.771 & 1.382 & 104.119 & 0.956 \\
\hline EDU & 35.376 & 1.310 & 41.771 & 1.687 \\
\hline INCFUT & 87.151 & 1.498 & 97.290 & 1.367 \\
\hline 3-meters & -1.168 & -0.011 & 70.517 & 0.686 \\
\hline MAIL & 503.621 & 4.490 & 494.096 & 4.737 \\
\hline VISIT & 63.589 & 0.501 & 121.475 & 1.003 \\
\hline RECFUT & 148.902 & 1.716 & 251.382 & 2.221 \\
\hline NUSEVAL & 101.403 & 0.963 & 85.216 & 1.066 \\
\hline RECREVAL & 189.006 & 2.289 & 161.454 & 2.218 \\
\hline TRUSFUND & 27.781 & 0.653 & 22.250 & 0.398 \\
\hline $\mathrm{R} 2$ & 0.12 & & 0.11 & \\
\hline Observation & 621 & & 1912 & \\
\hline Var & ection & & & \\
\hline $\mathrm{INC}$ & 0.004 & 3.381 & 0.969 & 3.376 \\
\hline AGE & -0.012 & -2.294 & -1.240 & -1.045 \\
\hline MALE & 0.485 & 3.166 & 85.341 & 2.467 \\
\hline EDU & 0.053 & 1.427 & 19.869 & 2.537 \\
\hline Constant & 4.474 & 10.545 & $\begin{array}{l}-79.396 \\
\end{array}$ & -0.790 \\
\hline
\end{tabular}




\section{IV.5 Comparison}

Table 12 summarizes the WTP estimations with the three different CV approaches. ${ }^{13}$

Table 12

\section{Mean WTP Estimations with Different CV Approaches}

\begin{tabular}{|c|c|c|c|c|}
\hline & \multicolumn{2}{|c|}{ Personal Interview } & \multicolumn{2}{|c|}{ Mail Survey } \\
\hline & 0 -meter & 3-meter & 0 -meter & 3-meter \\
\hline \multicolumn{5}{|l|}{ Open-ended approach } \\
\hline Mean Value of the WTP & 201 & 213 & 446 & 495 \\
\hline St. Var. of the WTP & 374 & 595 & 881 & 776 \\
\hline \# of observations & 95 & 88 & 67 & 70 \\
\hline \multicolumn{5}{|l|}{ Closed-ended approach } \\
\hline Mean Value of the WTP & 273 & 222 & 505 & 455 \\
\hline St. Var. of the WTP & 394 & 414 & 327 & 294 \\
\hline St. error of the mean WTP & 84 & 60 & 149 & 84 \\
\hline \# of observations & 232 & 230 & 227 & 216 \\
\hline \multicolumn{5}{|l|}{ Likelihood approach } \\
\hline \multicolumn{5}{|l|}{ Two-stage method } \\
\hline Mean Value of the WTP & 349 & 344 & 764 & 870 \\
\hline Mean St. Var. & 471 & 426 & 894 & 720 \\
\hline \# of observations & 175 & 161 & 144 & 142 \\
\hline \multicolumn{5}{|l|}{ Combined linear method } \\
\hline Mean Value of the WTP & 466 & 510 & 740 & 883 \\
\hline Mean St. Var. & 337 & 333 & 349 & 411 \\
\hline \# of observations & 148 & 147 & 162 & 158 \\
\hline
\end{tabular}

The results show that the open-ended approach produced the lowest estimation of the mean value of WTP and the SPC approach gave the highest estimation. The closed-ended approach gave a value in between but the value is not statistically significantly different from the one provided by the open-ended approach. The result that the value offered by the closed-ended

\footnotetext{
${ }^{13}$ The 0 -meter case should be employed for the comparison because the 3-meter case seemed less supportive by the respondents. Some of the observations with the 3-meter case may be subject to the scenario rejection bias, because the economy was very poor and it did not make much sense to many people that the water level of the lake should be increased - it should make more sense to prevent the lake from further deteriorating.
} 
approach is significantly lower than the value offered by the SPC approach is opposite to the finding of Wang and Whittington (2000), where the value obtained with the closed-ended approach is significantly higher than the value obtained with the SPC approach. People in Yerevan were more likely to give a negative answer to the Lake Sevan WTP question when only "yes" and "no" options were provided than when a spectrum of yes and no options (specifically, "definitely yes", "probably yes", "not sure”, "probably no", and "definitely no") were provided. But according to Wang and Whittington (2000), people in Sofia, Bulgaria, were more likely to give a positive answer to the Sofia air quality improvement WTP question when only yes and no options were given.

Table 12 shows that the results of the mail surveys are consistently higher than those of the personal interviews, which may demonstrate a downward bias caused by the interviewers. This finding conflicts with the study results obtained in the United States, which normally show an upward bias. This outcome should be understandable, however, because in Armenia, most households were very poor and would like to get financial support from the outside. The interview bias should be negative because people would not like the interviewers to feel they have enough income to support public programs such as the Lake Sevan Restoration Action Plan.

Education consistently shows a positive correlation with the variance. No conclusion can be drawn, however, on other variables even though income shows significantly positive in two of the three cases, while in the other case the coefficient is not significant. Because the models are constructed differently for the three different $\mathrm{CV}$ formats, the coefficients in the three models do 
not measure the same thing, and therefore, we should not expect that coefficients are the same. The variance of WTP should be determined by the uncertainty and the scale of WTP. To have a more sophisticated modeling on the variance function is beyond the scope of this study, but further research on this front is clearly warranted.

\section{Summary and Discussion}

This paper presents a contingent valuation study on people's willingness to pay for the protection of Lake Sevan conducted in Yerevan, Armenia. Three value elicitation formats open-ended, closed-ended, and SPC - were used in the study. Results show that the SPC approach produces a higher estimation of the mean willingness to pay, while the closed-ended approach and the open-ended approach give similar results. This is the opposite to the conclusion drawn in Wang and Whittington (2000) where a higher estimation with the closed-ended approach than with the SPC approach is reported of people's WTP for air question improvement in Sofia, Bulgaria. In Yerevan, people were more likely to give a negative answer when only yes and no options were provided to a WTP question for Lake Sevan water resources protection, while in Sofia, people were more likely to give a positive answer when only yes and no options were provided to a WTP question for Sofia air quality improvement.

The analyses also find that the mail surveys conducted in Yerevan produced a significantly higher estimation of willingness-to-pay than the personal interviews, which is contrary to the findings of previous studies conducted in the United States. In Armenia, a poor country, the potential interviewer bias might be negative in CV surveys on WTP for Lake Sevan protection. 
The research design and analysis have been based on the assumption that a respondent has a valuation distribution, rather than a single true value, in his/her mind. Heterogeneous WTP functions are explicitly modeled and estimated. Consistent results are found for the models of mean values with the three types of WTP data and modeling techniques. However, the variance functions seem to have different results. More research to help better understand the nature of individuals' valuation distributions is warranted.

The Lake Sevan study is the second study that adopts the SPC approach to directly measure individuals' valuation distributions. ${ }^{14}$ The improvements in the stochastic payment card design with this study include that a price of zero and more higher prices are included in the list of prices, and more numeric likelihood values are systematically presented for a respondent to indicate his/her possible answers to the different prices. It is the first time that a mail survey using the SPC approach has been successfully conducted, and no concerns emerged on using the SPC approach in the mail survey during the survey process, as most Armenians are well educated.

The SPC approach extends the previous research efforts in using multiple bounded models and certainty scales to improve the contingent valuation method, but explicitly recognizes the understanding that an individual's valuation is not a single number, but should have a distribution. Subjective probabilities are asked of respondents and used to estimate respondents' willingness to pay for a commodity or a service. More research on subjective probabilities and the possible design effects of the approach on WTP estimation is warranted. 
Furthermore, as discussed in Wang (1997a), other valuation approaches, such as the travel cost approach and the hedonic approach, may need to be modified if one accepts the idea that an individual's WTP is not a single number but rather has a distribution.

${ }^{14}$ The first study which uses the SPC approach was conducted in Bulgaria on air quality improvement in Sofia (Wang and Whittington 2000). 


\section{References}

Alberini, A., Boyle, K, and Welsh, M. 2003. "Analysis of Contingent Valuation Data with Multiple Bids and Response Options Allowing Respondents to Express Uncertainty", J of Envr. Econ. \& Mngmnt. 45, 40-62.

Berrens, R. P., Jenkins-Smith, H., Bohara, A. K, and Silva, C.L. 2002. "Further Investigation of Voluntary Contribution Contingent Valuation: Fair Share, Time of Contribution, and Respondent Uncertainty", J of Envr. Econ. \& Mngmnt. 44, 144-168.

Cameron, T.A. and Quiggin, J. 1994. "Estimation Using Contingent Valuation Data From: A 'Dichotomous Choice with Follow-up' Questionnaire”, J of Envr. Econ. \& Mngmnt. 24, 218-234.

Carson, R.T., W.M. Hanemann, R.J. Kopp, J.A., Krosnick, R.C. Mitchell, S. Presser, P.A. Ruun, and V.K. Smith, 1998, "Referendum Design and Contingent Valuation: The NOAA Panel's No-Vote Recommendation," Review of Economics and Statistics, 80(3), 484-487.

Champ, P., R. Bishop, T. Brown, and D. McCollum, 1997, "Using donation mechanisms to value nonuse benefits from public goods,” J of Envr. Econ. \& Mngmnt. 33, 151-163 (1997)

Clemen, Robert T., 1990, Making Hard Decisions, PWS-Kent Publishing Company, Boston.

Desvousges, W.H. \& Smith, Kerry. 1987. "Option Price Estimates for Water Quality Improvements: A Contingent Valuation Study for the Monongahela River", J. Envr. Econ. \& Mngmnt, 14, 248-267.

DuBourg, W.R., M.W. Jones-Lee, and G. Loomies, 1994, "Imprecise Preferences and the WTPWTA Disparity," J. Risk and Uncertainty 9, 115-133 (1994).

Edwards, Steven. 1988. "Option Prices for Ground water Protection”, J. Envr. Econ. \& Mngmnt, $15,475-487$.

Fischoff, Baruch, and Furby. 1988. "Measuring Values: A Conceptual Framework for Interpreting Transactions with Special Reference to Contingent Valuation of Visibility." Journal of Risk and Uncertainty. June. pp. 147-84.

Graham, Daniel A. 1981. "Cost - Benefit Analysis under Uncertainty", American Economic Review. Vol. 71, pp. 715-725.

Hanemann, W.M. 1984. "Welfare Evaluations in Contingent Valuation Experiments with Discrete Responses", Amer. J. Agr. Econ. Vol. 66, pp. 332-341.

Layton, David F. 2000. "Random Coefficient Models for Stated Preference Surveys", J. of Envr. Econ. Mngmnt. 40, 21-36. 
Li, Chuan-Zhong, Leif Mattsson. 1995. "Discrete Choice under Preference Uncertainty: An Improved Model for Contingent Valuation", J. of Envr. Econ. Mngmnt. 28, 256-269.

Mitchell, R.C. \& Carson, R.T. 1989. Using Surveys to Value Public Goods: The Contingent Valuation Method, Resources for the Future, Washington, D.C.

Nunes, P. A.L.D., and Schokkaert, E. 2003. "Identifying the Warm Glow Effect in Contingent Valuation", J. of Envr. Econ. Mngmnt. 45, 231-245.

Ready, Richard C., Whitehead, John C. \& Blomquist, Glenn C. 1995. "Contingent Valuation When Respondents Are Ambivalent", J. of Envr. Econ. Mngmnt. 29, 181-196.

Rowe, Robert D., W. D. Schulze, \& W. S. Breffle. 1996. "A Test for Payment Card Biases”, J. Envr. Econ. Mngmnt. 31(2), 178-185.

Wang, Hua. 1997a. Contingent Valuation of Environmental Resources: A Stochastic Perspective, Ph.D. Dissertation, Department of Environmental Sciences and Engineering, School of Public Health, University of North Carolina at Chapel Hill, Chapel Hill, North Carolina, USA.

Wang, Hua. 1997b. "Treatment of Don't-Know Responses in Contingent Valuation Surveys: A Random Valuation Model”, J. of Envr. Econ. Mngmnt. 32, 219-232.

Wang, Hua and Dale Whittington, 2000, Willingness to pay for air quality improvements in Sofia, Bulgaria, World Bank Policy Research Working Paper \#2280, Washington, DC 20433.

Wallsten, T.S. and D. V. Budescu, 1983, "Encoding subjective probabilities: A psychological and psychometric review," Management Science, 29 (2), 1983.

Wallsten, T.S. and D. V. Budescu, 1995, "A review of human linguistic probability processing: General principles and empirical evidence", The Knowledge Engineering Review, 10:1, 4362, 1995.

Welsh, M.P. and Poe, G.L., 1998, "Elicitation Effects in Contingent Valuation: Comparison to a Multiple Bounded Discrete Choice Approach", J. of Envr. Econ. Mngmnt. 36, 170-185.

World Bank, 1999, Armenia: Lake Sevan Action Program, Washington, DC 20433. 
Appendix I

Example of a Stochastic Payment Card

\begin{tabular}{|c|c|c|c|c|c|}
\hline $\begin{array}{c}\text { Monthly cost } \\
\text { to the } \\
\text { household } \\
\text { (in AMD) }\end{array}$ & $\begin{array}{c}\text { Definitely } \\
\text { No }\end{array}$ & Probably No & Not Sure & Probably Yes & $\begin{array}{c}\text { Definitely } \\
\text { Yes }\end{array}$ \\
\hline \hline 0 (free) & $0 \%$ & $10 \% 20 \% 30 \% 40 \%$ & $50 \%$ & $60 \% 70 \% 80 \% 90 \%$ & $100 \%$ \\
\hline 100 & $0 \%$ & $10 \% 20 \% 30 \% 40 \%$ & $50 \%$ & $60 \% 70 \% 80 \% 90 \%$ & $100 \%$ \\
\hline 200 & $0 \%$ & $10 \% 20 \% 30 \% 40 \%$ & $50 \%$ & $60 \% 70 \% 80 \% 90 \%$ & $100 \%$ \\
\hline 400 & $0 \%$ & $10 \% 20 \% 30 \% 40 \%$ & $50 \%$ & $60 \% 70 \% 80 \% 90 \%$ & $100 \%$ \\
\hline 600 & $0 \%$ & $10 \% 20 \% 30 \% 40 \%$ & $50 \%$ & $60 \% 70 \% 80 \% 90 \%$ & $100 \%$ \\
\hline 800 & $0 \%$ & $10 \% 20 \% 30 \% 40 \%$ & $50 \%$ & $60 \% 70 \% 80 \% 90 \%$ & $100 \%$ \\
\hline 1,000 & $0 \%$ & $10 \% 20 \% 30 \% 40 \%$ & $50 \%$ & $60 \% 70 \% 80 \% 90 \%$ & $100 \%$ \\
\hline 2,000 & $0 \%$ & $10 \% 20 \% 30 \% 40 \%$ & $50 \%$ & $60 \% 70 \% 80 \% 90 \%$ & $100 \%$ \\
\hline 5,000 & $0 \%$ & $10 \% 20 \% 30 \% 40 \%$ & $50 \%$ & $60 \% 70 \% 80 \% 90 \%$ & $100 \%$ \\
\hline 10,000 & $0 \%$ & $10 \% 20 \% 30 \% 40 \%$ & $50 \%$ & $60 \% 70 \% 80 \% 90 \%$ & $100 \%$ \\
\hline 20,000 & $0 \%$ & $10 \% 20 \% 30 \% 40 \%$ & $50 \%$ & $60 \% 70 \% 80 \% 90 \%$ & $100 \%$ \\
\hline
\end{tabular}




\section{Appendix II \\ Excerpts from the Questionnaire}

\section{$\underline{\text { Lake Sevan Action Plan }}$}

While dealing with its severe economic situation, the government of the Republic of Armenia recently expressed the interest to adopt a number of actions to protect Lake Sevan from further, and perhaps irreversible degradation, and to make an attempt at improving the quality.

The actions currently under discussion include:

a. Limiting water releases to 370 million $\mathrm{m} 3$ per year;

b. construction of the Vorotan Tunnel;

c. completion of the Yeghvard reservoir;

d. combinations of the above.

With different combinations of these actions, two targets which may be achieved are: 1) preventing any further lowering of the water level of the lake; and 2) raising the level of the lake by 3 meters in the next 15 years. Without any action, the water level of the lake is predicted to drop by 2 meters more in the next 10 years. (Eleven questions about the action plan and the Lake Sevan are omitted.)

\section{Consequences of the Lake Sevan Protection Action Plan}

We would like to know how strongly you may support for a Lake Sevan Action Plan which may introduce some cost to your household. Let's focus on the possible plan which targets raising the water level of the lake by 3 meters in 15 years. To meet the target, actions may include: 1 . Limiting the water release to 370 million $\mathrm{m} 3$ per year from Lake Sevan, and 2. Constructing the Vorotan Tunnel.

I think you would like to know what are the consequences of a water level increase by 3 meters before you make decision on whether to support such an action plan. The economy and the ecosystem of the lake are too complex, however, to predict precisely the effects such a plan would have. [Enumerator: please show graph and picture] Presented here is a general description of the possible consequences. A summary of the impacts include:

a. There would be no further water level decrease, a major concern of most Armenians;

b. Water quality in the lake would be improved, benefiting fish and bird populations;

c. The ecosystem of the lake would be improved and thus it would be better for recreational and tourist activities;

d. The commercial fishery could also be increased;

e. More water is available after the increase of the lake level for agricultural irrigation and in times of drought, and therefore agricultural output could be better protected;

f. In the future, when necessary, the stock of water could be used for more energy generation;

g. Others you specify.

\section{Costs of the Action Plan}

Of course there are costs to Armenians in implementing this Lake Sevan Restoration Action Plan. Some Armenians may be negatively affected by the two action options - limiting water release to 370 million $\mathrm{m} 3$ per year from Lake Sevan and constructing the Vorotan Tunnel. Financial support from different groups of Armenians, such as households like yours, are also necessary. The Armenian Diaspora outside Armenia would also be asked for financing this plan by making donations. 


\section{Plan Implementation:}

To implement such a plan, a Lake Sevan Trust Fund would be established. Citizens in Armenia would be asked to pay through their utility bill and the fund collected would go into the Trust Fund (for $\mathbf{3}$ years). The Fund's sole purpose would be to finance the efforts of the action plan and would contribute all of the proceeds to the plan.

The Fund would be managed and administered by a Board of Governors comprising various interest groups so as to minimize any possible bias and to create an atmosphere of trust. Although this list is not exhaustive, the Board would at the very least consist of people form the Ministry of Nature Protection, environmental and community groups from the USA, France and Armenia as well as local residents of the Sevan basin area. Each member of the Board would have an equal vote and there would not be any overriding veto power by any one individual in the Board, thus there would be no overruling Chairman present in the Board. The activities of the Board would be completely transparent and all the activities supported by the Fund would have to be approved by a unanimous decision of the Board. You could thus have complete trust in the allocation of the money toward protecting and restoring Lake Sevan.

\section{Willingness-to-Pay Question (Stochastic Payment Card)}

(Read) Considering your current income, as well as your expenses for housing, food, utilities, clothing, entertainment, savings, etc., please think about how much you would be willing to pay to support such an action plan. Assume that your monthly payment would be collected by a group of people delegated by the Trust Fund management.

I want you to suppose that the people of Armenia had an opportunity to vote for such a plan with a certain cost to Armenian people. If the majority of people voted for the plan, the plan would go into effect and every household would have to pay. If the majority of people voted against the plan, no one would have to pay and the level of water in Lake Sevan would continue to decrease. Remember that the sum collected would be used entirely for implementing this plan.

Please tell us how likely you would be willing to vote for the lake restoration plan if there was a cost to your household in order to increase the level of the lake by 3 meters. In other words, we want to know how likely you would pay for the action plan for the several specified amounts listed below. [Enumerator: Please show the stochastic payment card]

There is no right or wrong answer; we really would like to know how your household values this proposal. If the number indicated in the left column [Enumerator: Please show the payment range] corresponds to the necessary monthly payment (for 3 years) for the implementation of the Lake Sevan Action Plan, how likely is it you would vote for the plan? [Enumerator: Please circle an answer for each of the prices] 


\section{Appendix III \\ Charts for Changes of the Lake}

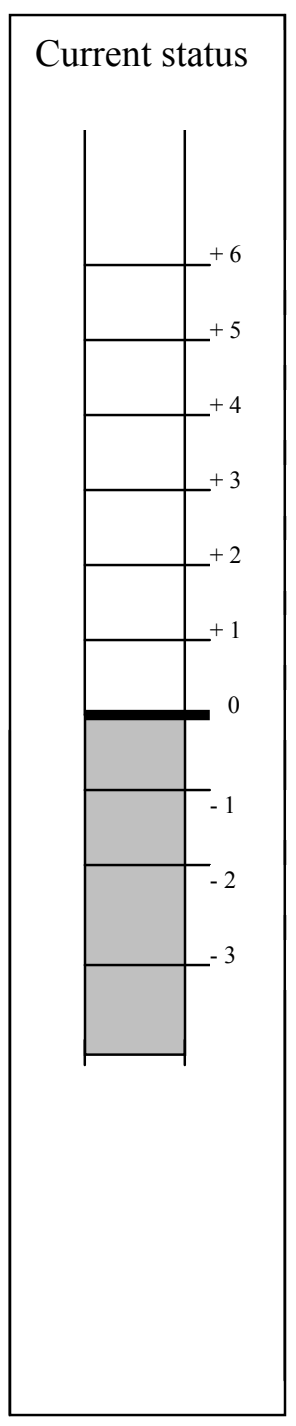

Current situation \& no change

\section{Expected impacts}

Fish: Slight increase in general catch, but endemic trout still endangered

Birds: No further loss of bird species

Plants: Increased number and variety of aquatic plants

Water quality: a little bit better

Power generation: small decrease today, some increase in the future

Agriculture irrigation: less water use today, but greater availability in the future
Change (m)

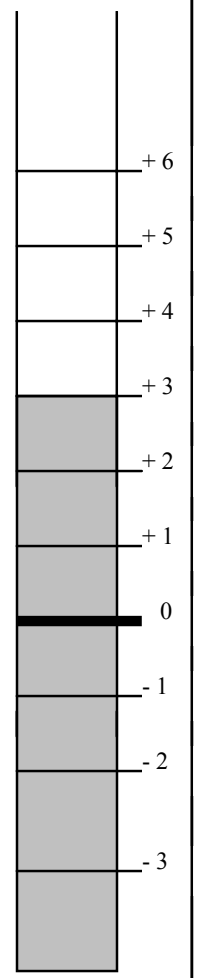

\section{Expected impacts}

Change (m)

Fish: Decrease in general catch, and endemic trout become extinct

Birds: Continued decrease in bird species due to wetlands habitat destruction

Plants: Decreased number and variety of aquatic plants

Water quality: a lot worse

Power generation: small decrease today, larger decrease in the future

Agriculture irrigation: less water use today and even less availability in the future

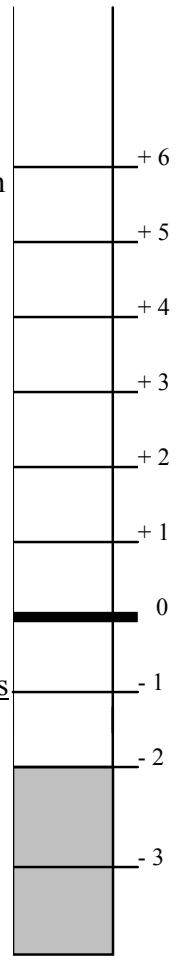

No Action: 2 meters decrease in 10 years 


\section{Appendix IV \\ Graphs for the Changes of the Lake}

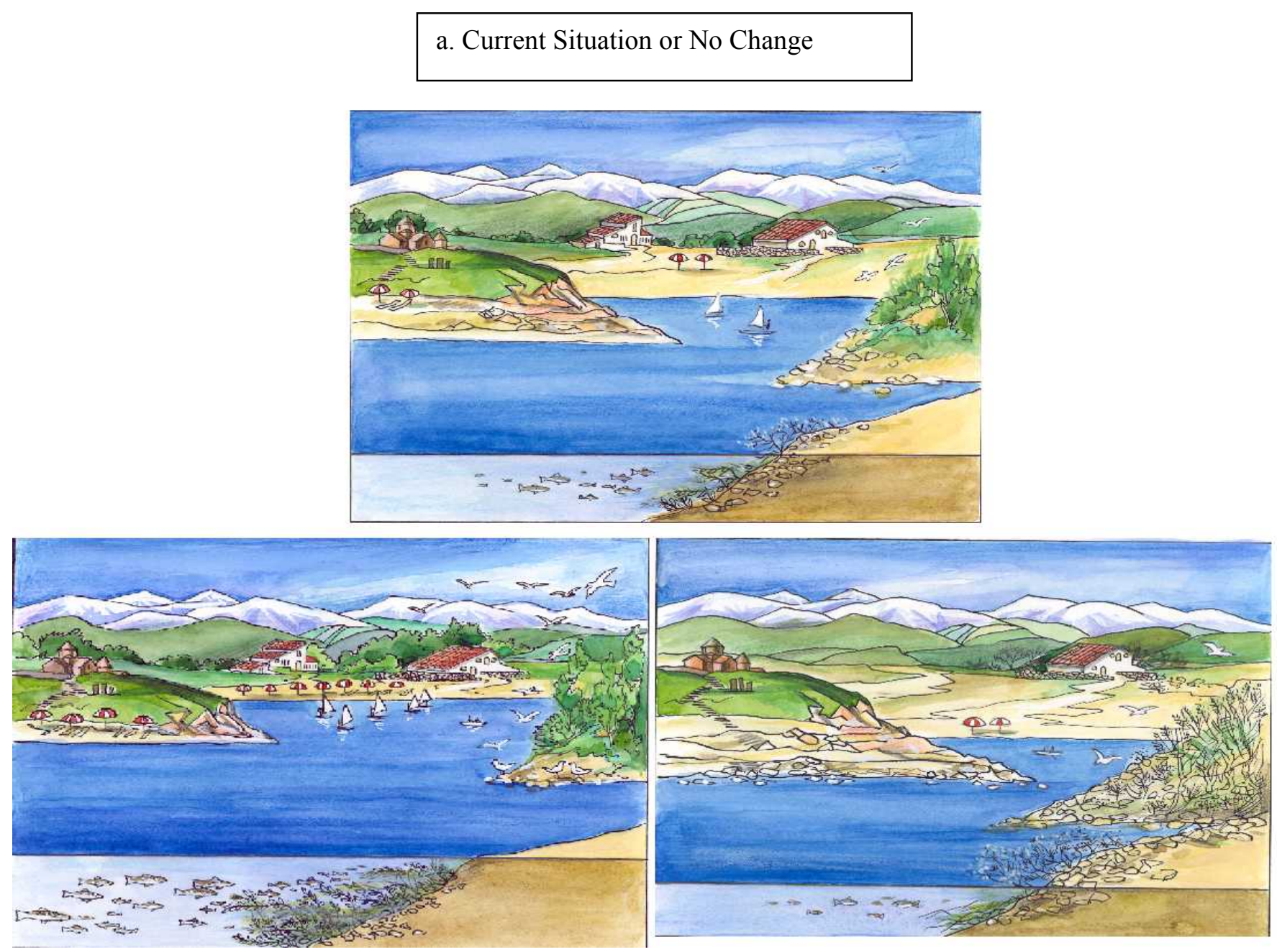

b. 3 meters increase

c. 2 meters decrease 